\title{
Configurações
}

Revista de sociologia

15 | 2015

Género, Sexualidade e Afetos

\section{Homens e expressão emocional e afetiva: vozes de desconforto associadas a uma herança instituída}

Men and Emotional and Affective Expression: Voices of discomfort connected to an established legacy

Les hommes et l'expression émotionnelle et affective: Voix d'inconfort liés à un héritage laissé

\section{Luís Santos}

\section{OpenEdition}

\section{Journals}

Edição electrónica

URL: http://journals.openedition.org/configuracoes/2593

DOI: $10.4000 /$ configuracoes.2593

ISSN: 2182-7419

\section{Editora}

Centro de Investigação em Ciências Sociais

\section{Edição impressa}

Data de publição: 30 Junho 2015

Paginação: 31-48

ISBN: 1646-5075

ISSN: 1646-5075

\section{Refêrencia eletrónica}

Luís Santos, «Homens e expressão emocional e afetiva: vozes de desconforto associadas a uma herança instituída », Configurações [Online], 15 | 2015, posto online no dia 01 setembro 2015 consultado o 19 abril 2019. URL : http://journals.openedition.org/configuracoes/2593 ; DOI : 10.4000/ configuracoes. 2593

Este documento foi criado de forma automática no dia 19 Abril 2019. 


\title{
Homens e expressão emocional e afetiva: vozes de desconforto
} associadas a uma herança instituída

\author{
Men and Emotional and Affective Expression: Voices of discomfort connected to \\ an established legacy \\ Les hommes et l'expression émotionnelle et affective: Voix d'inconfort liés à un \\ héritage laissé
}

Luís Santos

\section{Introdução}

1 As atuais conceções alternativas a um modelo sexológico dominante, descrito por Plummer (2005) como alicerçado na ideia de uma sexualidade masculina natural, instintiva, centrada no pénis e numa procura incessante pelo orgasmo, associada à procriação e à heterossexualidade como sinónimo de normalidade (Vaz, 2003), estabelecem que as sexualidades humanas são marcadas por questões simbólicas ligadas a questões de poder. Na verdade, o género encontra-se associado a um conjunto de normas e prescrições sobre uma diversidade de aspetos da vida das pessoas, incluindo as experiências e formas de expressão emocional e afetiva (Zammuner, 2000).

2 No quadro específico dos homens e das masculinidades, a conceção de masculinidade hegemónica, ensinada desde cedo pelas diferentes instâncias socializadoras (Connell, 1995) e incorporada (Bourdieu, [1998] 1999) por todos os homens ao longo do seu processo desenvolvimental, independentemente da pluralidade das suas variáveis sociodemográficas, entre elas, a orientação sexual, é considerada um elemento-chave para a forma como estes homens irão, ao longo das suas vidas, gerir, para além das suas construções identitárias, a expressão das suas emoções e dos seus afetos em diferentes palcos do quotidiano.

$\mathrm{O}$ presente artigo parte do pressuposto de que, em geral, os homens, sobretudo no 
contexto da modernidade ocidental, aprenderam, em diferentes palcos offline (por exemplo, família, amigos, escola, local de trabalho, intimidade), a regular a expressão emocional e afetiva, dada a incorporação de um modelo dominante que associa a razão à masculinidade e a emoção à feminilidade (Vale de Almeida, 1995). Para o efeito, são utilizados dados empíricos de um projeto de investigação já concluído, levado a cabo pelo autor, incidindo sobre os estudos de género, masculinidades e expressão emocional e afetiva.

\section{Scripts sexuais e regulação da expressão emocional e afetiva}

A teoria dos scripts sexuais inscreve-se na corrente do interacionismo simbólico (Simon e Gagnon, 1986). Os mesmos autores introduziram o termo script sexual, a fim de dar conta do carácter construído da sexualidade, distanciando-se do postulado biológico tradicionalmente associado à mesma. Os scripts sexuais constituem um caso específico de scripts sociais e podem ser entendidos como esquemas socialmente construídos de atribuição de significação e de orientação da ação (Alferes, 1997). Nesse sentido, a noção de script corresponde "essencialmente [a] uma metáfora para conceptualizar a produção de comportamentos no interior da vida social” (Simon e Gagnon, 1986: 98), entre eles, os dedicados à expressão emocional e afetiva.

Deste modo, e partindo de uma conceptualização da expressão emocional e afetiva como resultado de um processo de construção psicossocial, abordaremos a expressão emocional e afetiva como produto de uma regulação cultural assente em scripts que oprimem os homens, independentemente da sua orientação sexual. Após focarmos a atenção no contributo específico da família ao longo deste processo, concluímos com uma análise da emergência e das consequências da construção do desempenho e da fachada pessoal neste domínio.

\subsection{A regulação cultural das emoções e do afeto}

5 Tradicionalmente considerada um assunto da expressão e da experiência individuais, o estudo das emoções tem captado o interesse de uma diversidade de disciplinas científicas. Tal interesse tem sido justificado através do facto de a emoção, para além de ser um tema individual, constituir um tema histórico, sociológico e cultural (Frevert, 2011; Oatley e Jenkins, 2002). Não será, por isso, de estranhar o facto de Strongman ([1996] 2004) reconhecer a teoria feminista como uma teoria de impacto crescente na teoria e na investigação da emoção, em particular no que respeita à inequívoca importância do reconhecimento do género nesta matéria. De resto, as culturas ocidentais modernas partilham a convicção de que as mulheres são mais emotivas do que os homens (Fischer e Manstead, 2000), resultando daqui uma oposição binária entre emoção e razão, fortemente associada, respetivamente, à feminilidade e à masculinidade (Lloyd, 1984).

6 A acompanhar esta tese, Lutz (1990) acrescenta que alguma literatura especializada atribui à mulher maior emocionalidade e ao homem maior racionalidade. Lupton (1998), ao analisar a dicotomia entre racional e emocional em associação com a identidade de género, destaca que a expressão de certas emoções, tais como o receio e a vulnerabilidade, tem sido mais associada à mulher. Pelo contrário, emoções como a raiva, a fúria ou a 
agressividade têm sido associadas ao homem. Do ponto de vista de uma possível tipologia da emoção associada ao género, espera-se que as mulheres experimentem um vasto leque de emoções consideradas mais positivas, ao passo que aos homens são atribuídos apenas alguns tipos, particularmente negativos.

Contrariando a ideia de ordem natural das coisas (Bourdieu, [1998] 1999), as teorias que derivam do construcionismo social consideram o facto de as emoções serem socialmente construídas (por exemplo, Harré, 1986; Oatley, 1993). De acordo com a perspetiva construcionista social, considera-se que, nas pessoas adultas, ocorrem estímulos internos e externos, cuja interpretação é responsável pela mediação entre os estímulos e qualquer resposta emocional que se lhes possa seguir. Excluem-se aqui as crianças recém-nascidas, dado que nessa fase do ciclo vital as emoções consistem em reações imediata e biologicamente determinadas. $\mathrm{O}$ mesmo quer dizer que qualquer cultura tem os seus próprios padrões distintivos de emoções que emergem das práticas sociais, conferindo à expressão emocional uma certa fluidez (Strongman, [1996] 2004).

Neste contexto, a emoção, progressivamente afastada da esfera do individual e do essencialismo biológico, tem sido representada, pelo construcionismo social, como um constructo cultural e discursivo. Esta abordagem pressupõe a tentativa de descrever a forma como as emoções são socialmente construídas nos adultos, bem como aquilo que as emoções cumprem em termos de papéis e deveres sociais (Oatley e Jenkins, 2002).

De acordo com tal entendimento, os diferentes conceitos de emoção devem ser encarados como elementos de práticas ideológicas locais, que envolvem diferentes negociações sobre o significado dos eventos, sobre direitos e moralidade, sobre o controlo dos recursos e, em última análise, sobre todas as esferas da vida social. Assim, as emoções são encaradas como uma espécie de idioma que define e estabelece as relações sociais (Lutz e Abu-Lughod, 1990).

10 Neste campo do discurso das emoções, conforme referem Lutz e AbuLughod (1990), a sociabilidade e as relações de poder são dois aspetos centrais. Deste modo, a união entre discurso e realidade social, cultural, política ou de outra ordem, não se localiza nem no sujeito psicológico que fala, nem nas suas intenções, nem na sua pertença a grupos ou ideologias bem definidas, mas antes nas condições de produção desse discurso (Nogueira, 2001).

Devido ao seu carácter construtivo da realidade social, o discurso manifesta um efeito decisivo no modo como o mundo social se configura. As práticas discursivas são, afinal, práticas sociais, produzidas através de relações de poder concretas, num determinado contexto espácio-temporal. Tais relações remetem para certos efeitos que regulam e controlam a ordem social.

12 A tese de que as emoções são predominantemente sociais é igualmente corroborada por Goffman ([1959] 1993), ao esclarecer que qualquer ser humano poderá vivenciar um conflito interior sempre que o papel social a si reservado não coincide com aquilo que o mesmo interiormente possa sentir em determinada ocasião. A este propósito, Goffman ( Ibidem) refere que construímos apresentações dramáticas de nós mesmos aos outros, (re)criando a realidade social em que vivemos como uma espécie de representação, ainda que, por vezes, à custa de alguns aspetos dolorosos e insatisfatórios para a vida pessoal.

13 Este autocontrolo a que nos referimos funciona como um comportamento que é construído e aprendido, a fim de evitar a vergonha e o julgamento, associando a apresentação de si de acordo com as expectativas heteronormativas da sociedade (Elias, 
2002; Frevert, 2011; Oatley e Jenkins, 2002). Deste modo, os homens aprenderam a ser homens, esforçando-se por tornar visível a sua virilidade, através dos gestos, dos discursos e dos temas das conversas, amplamente vincadas pelo erotismo heterossexual, num comportamento claramente performativo (Scheff, 1988; Vale de Almeida, 1995).

É justamente com base nesta linha de raciocínio que Gross e Thompson (2007) identificam três aspetos associados ao conceito de regulação da expressão emocional que, por si só, justificam uma atenção particular. Desde logo, há uma aceitação explícita quanto à possibilidade de as pessoas poderem regular a expressão das suas emoções, quer pela diminuição da intensidade com que o fazem, quer pela sua intensificação; por outro lado, os autores sugerem que a regulação da expressão emocional pode revestir-se de um carácter consciente, destacando como exemplo o facto de, regra geral, procurarmos esconder o medo que possamos experimentar quando nos sentimos rejeitados; por fim, e na generalidade das ocasiões, não são elaboradas suposições prévias sobre se uma particular forma de regulação da expressão emocional é necessariamente boa ou má, melhor ou pior que a outra.

Neste contexto, e relembrando o facto de a masculinidade hegemónica (Connell, 1995) se encontrar associada à ideia de independência e autonomia, tornam-se claras as razões quanto às dificuldades geralmente sentidas pelos homens em admitir as suas necessidades emocionais, em particular as relacionadas com a tristeza ou a vulnerabilidade (Scheff, 1988; Seidler, 2007; Santos e Nogueira, 2011, 2013). Nesse sentido, urge compreendermos a expressão emocional dos homens num quadro mais vasto, no qual estes aprenderam a afirmar publicamente a sua masculinidade.

\subsection{A socialização da regulação emocional na família}

16 Aceite como a mais antiga das instituições sociais humanas, a família apresenta-se com um carácter universal, embora com variações de sociedade para sociedade e de geração para geração quanto às suas formas de organização e funcionamento. De acordo com Saraceno e Naldini ([1992] 2003), a família revela-se como um dos lugares privilegiados de construção social da realidade, mediante a construção social dos acontecimentos e relações aparentemente mais naturais. Sendo da ordem do social, a existência da família não é imune a um conjunto de regras que emanam da sociedade (Leandro, 2001).

17 No quadro da socialização da expressão emocional e afetiva, Braconnier ([1996] 1998) afirma que a análise do contexto familiar é fundamental. Brody (2000) reconhece esta importância e sustenta que os pais tendem a educar os seus filhos no sentido de estes se conformarem às regras sociais. Tal significa uma tendência para enfatizar o controlo da expressão emocional e afetiva no caso dos filhos e, no caso das filhas, o controlo da agressão. Estas últimas são, sugere o autor, mais encorajadas do que os rapazes a falar dos seus problemas.

Não será, pois, por acaso que diferentes autores (e.g., Saarni, 1988; Zeman e Garber, 1996) revelam que as crianças se consciencializam, desde cedo, da expectativa social quanto à regulação da sua expressão emocional em frente aos seus pares, antecipando a rejeição, o ridículo ou advertências caso não estejam em conformidade com as regras de exibição. Por outro lado, reportando-se ao estudo da expressão emocional na fase adulta, e a apoiar este argumento, Fabes e Martin (1991) encontraram nas suas pesquisas resultados que sugeriram que os adultos são capazes de distinguir entre expressões emocionais 
masculinas e femininas, sendo que as diferenças documentadas se reportam apenas às formas de expressão.

\subsection{Desempenho e fachada pessoal} envolvem-se mais facilmente com os seus pares em atividades que incluam trabalhos de equipa com regras conformadas com a ordem social (Lever, 1976). Outros estudos (por exemplo, Tannen, 1990) mencionam que, mesmo quando se encontram com o seu melhor amigo, os rapazes em idade escolar tendem a conversar sobre assuntos como desporto ou programas televisivos, facto que contrasta, de acordo com os mesmos resultados, com a mais habitual partilha de problemas e de emoções entre as raparigas também em idade escolar. públicas a que as diferentes formas de expressão emocional estão sujeitas, cuidando assim de salvaguardar as suas imagens (Fivush e Buckner, 2000). Na mesma linha, Zemane e Shipman (1996) descrevem, nos seus estudos sobre género e expressão emocional envolvendo crianças de ambos os sexos, que as meninas são mais contidas na forma como reportam a tristeza. Mais especificamente, estas expressam a tristeza através da verbalização ou do choro, ao passo que os meninos expressam a tristeza através da agressão. 

condição paradoxal: se, por um lado, a inibição dos sentimentos é uma das características cruciais da masculinidade hegemónica (Connell, 1995), por outro, a mesma é nociva no que concerne ao seu impacto na saúde e interação social. Este paradoxo não é passível de ser resolvido facilmente, dado que a restrição da emocionalidade está intimamente ligada à construção da masculinidade hegemónica. Nesse sentido, a natureza genderizada da comunicação emocional cria um contexto de interação no qual os rapazes e os homens não aprendem a falar de emoções que impliquem vulnerabilidade. Como resultado, os homens tendem a negar a experiência de determinadas emoções, ocultando a sua expressão. Em situações em que a desilusão, a vergonha, a tristeza, o medo ou a culpa não possam ser negados, ou disfarçados convenientemente pela fachada, estes são, regra geral, percecionados como ameaças à identidade masculina.

\section{Notas metodológicas}

Os dados empíricos seguidamente apresentados fazem parte de um projeto de investigação mais alargado, já terminado, intitulado Tornar-se homem: Dramaturgias em torno das apresentações de si, das emoções e dos afetos em palcos offline $e$ online (Santos, 2009). Trata-se de uma investigação inscrita nos estudos de género e das masculinidades, cujo objetivo principal consistiu em problematizar diferentes dramaturgias em torno das apresentações de si, das emoções e dos afetos, em diferentes palcos offline (por exemplo, família, colegas, amigos, local de trabalho, intimidade) e online (por exemplo, páginas pessoais, blogues, salas de conversação, redes sociais). Essa investigação, qualitativa e mediada por computador, recorreu à entrevista em profundidade, semiestruturada, realizada online, e envolveu um total de 34 indivíduos, distribuídos equitativamente por dois estudos autónomos, que se apresentaram como homens em diferentes salas de conversação de duas redes sociais.

Serão aqui apenas apresentados e discutidos os dados de um dos três temas identificados no Estudo 1, relativo às sexualidades socialmente normativas, no qual participaram 17 indivíduos que se identificaram como heterossexuais, com idades compreendidas entre os 26 e os 55 anos. Do total, três são casados, sete são divorciados e os restantes cinco são solteiros. Dois vivem em união de facto e seis são pais. Em termos de habilitações académicas, dois têm o 9.ำ ano de escolaridade, cinco têm o $12 .{ }^{\circ}$ ano e dez têm formação superior. Quatro são professores, dois advogados, um assistente social, um psicólogo, dois administrativos, um eletromecânico, dois chefes de produção, um pintor da construção civil e um medidor orçamentista. Dois são estudantes. Em termos de situação face à profissão, apenas um dos participantes está desempregado. Em comum, e em conformidade com o critério de inclusão no estudo, todos os participantes vivenciaram, até à data da entrevista, uma rutura amorosa por si considerada significativa. Tal opção prendeu-se com o facto de esta rutura nos oferecer maiores probabilidades de cada participante poder refletir sobre a gestão de emoções próximas da vulnerabilidade não apenas no abstrato, mas apoiados nas suas próprias experiências.

Foi deixado ao critério de cada participante o recurso à imagem, via webcam, durante a entrevista. Neste aspeto, as experiências foram diversas, ainda que a maior parte dos participantes tenha optado por não recorrer ao uso da imagem. Contudo, outros houve que, durante a realização da entrevista, optaram por ligar a webcam. A duração das entrevistas oscilou entre as duas e as quatro horas. Os dados foram analisados, num 
primeiro momento, através da análise temática (Braun e Clarke, 2006) e, depois de identifi cados os temas no corpus de análise, através da análise foucaultiana do discurso (Willig, 2003). Os dados analisados no presente artigo reportam-se ao tema "sexualidades masculinas e domesticação emocional e afetiva".

\section{Sexualidades masculinas e domesticação emocional e afetiva}

Por "sexualidades masculinas e domesticação emocional e afetiva" assumem-se as configurações e interpretações em torno da expressão emocional e afetiva em palcos offline. Dos discursos relacionados com o tema sobressaíram duas construções discursivas, a saber: Máscara para homem e Homens por detrás da máscara.

Máscara para homem resulta das várias configurações e interpretações construídas pelos participantes, a propósito da expressão emocional e afetiva em palcos offline, em geral, e à expressão emocional e afetiva socialmente (des) autorizada aos homens, em particular. Tais configurações desenvolveram-se em torno da seguinte pergunta de partida: Em seu entender, qual o lugar das emoções e dos afetos na vida quotidiana?

Homens por detrás da máscara emerge dos discursos dos participantes habitualmente silenciados em palcos offline e refere-se às dificuldades ocasionadas por uma hegemonia que associa, em geral, a expressão emocional e afetiva às mulheres. Inclui, ainda, as estratégias de superação ensaiadas pelos participantes de forma a encontrar espaços de expressão mais protegidos. Tais configurações desenvolveram-se a propósito da seguinte pergunta de partida: Como é que habitualmente lida com as suas emoções, em particular quando se sente mais triste?

\subsection{Máscara para homem}

31 Como referimos, Máscara para homem refere-se à expressão emocional e afetiva em contextos que vão desde a família, aos colegas, aos amigos e à intimidade. Contempla, ainda, a visão social que, na perspetiva dos participantes, existe a este respeito. A expressão emocional e afetiva foi associada por diversos participantes a um conjunto de ditos e interditos gerados por "uma sociedade que castra muito a parte emotiva do homem" (E1). De qualquer forma, e pese embora os homens se encontrarem, em geral, mais condicionados do que as mulheres no que diz respeito à expressão emocional e afetiva, de acordo com todos os discursos, as mulheres terão outro tipo de condicionamentos, conforme podemos testemunhar pelas passagens discursivas que se seguem:

"Se um homem não tem a mesma liberdade que uma mulher para chorar, não é menos verdade que as mulheres, se se mostrarem muito irritadas, passam a ser chamadas de histéricas. E se forem mais agressivas, então aí correm mesmo o risco de serem vistas como maluquinhas e escutarem frases do tipo: vê se te internas" (E29). "Temos as mesmas emoções que as mulheres. 0 que acontece é que não as podemos mostrar da mesma maneira. Acho que as mulheres estão muito mais autorizadas a chorar" (E17).

Neste seguimento, e reconhecendo o facto de as emoções fazerem "parte da nossa vida" (E6), alguns participantes referiram que a expressão emocional e afetiva depende do contexto social em que cada pessoa se posiciona: 
"As emoções fazem parte da nossa vida. Nós, homens recalcamos a maior parte delas e depois podemos demonstrar uma ou outra. Quando estamos zangados, por exemplo" (E6). "Diria que, na sociedade, há emoções ditas aceitáveis num homem. A raiva ou a ira serão dois exemplos. (...) pelo menos, é o que nos ensinam. Infelizmente, uns mais outros menos, acabamos por ceder a essas pressões sociais. Acho que todos vamos usando as nossas máscaras" (E26).

A expressão emocional e afetiva foi, ainda, apontada como suscetível de interpretações enviesadas, construídas por terceiros sobre aquele/a que protagoniza essa expressão:

“As formas como expressamos as nossas emoções são muitas vezes usadas pelos outros para nos caracterizarem. Daí que se um homem chora em público pode ser um problema. Quero com isto dizer que podem achar, e às vezes até dizem, que não estamos a ter um comportamento de homem" (E3).

Os participantes associaram a expressão emocional e afetiva a demonstrações socialmente percebidas como sinais de fraqueza, em particular as que impliquem vulnerabilidade e quando protagonizadas por homens. Nesse sentido, justificaram a necessidade de controlar, como forma de proteção da imagem de si, a expressão emocional e afetiva, sobretudo na presença de terceiros:

"É considerado sinal de fraqueza ser emotivo, em particular no nosso caso [dos homens]. Foi isso que nos ensinaram e continuam a ensinar. A nossa educação privilegia a racionalidade. Por exemplo, as empresas só recentemente é que pensam no capital emocional, mas é curioso porque a forma como o pensam é a de ensinar os colaboradores a controlarem as suas emoções, não a expressá-las e a compreendê-las. Ensinam-nos a controlar a pressão, não a descomprimi-la" (E31).

Face a este encadeamento, os participantes foram unânimes em considerar que, em geral, o ser humano não lida bem com a expressão emocional e afetiva e menos ainda com a sua partilha com terceiros, ainda que a mesma tenha sido considerada importante:

“Acho que não lidamos muito bem com a expressão das nossas emoções. Eu tenho uma tendência cada vez maior em guardá-las para mim, escondendo-as dos outros. De uma forma geral, todas as pessoas apregoam que devemos ser sinceros, mas isso nem sempre traz bons resultados. Em termos de partilhar as emoções, a coisa complica-se, daí optar por, em geral, reprimir" (E7).

Alguns participantes mostraram ser da opinião de que a sociedade em que vivem é uma sociedade de "pura emoção" (E2). No entanto, os mesmos concordaram que a expressão emocional e afetiva não está isenta de repressões. Face a este aparente paradoxo, quisemos apurar as explicações possíveis.

"Eu creio que vivemos numa sociedade de pura emoção. O que me parece é que se vai buscar outras emoções para colmatar as principais, sobretudo por não nos ser fácil expressá-las face a face. As pessoas, em geral, não lidam bem com a expressão emocional umas diante das outras. Mais facilmente dizem a um gato ou a um cão quanto gostam dele do que a um amigo" (E2). "A nossa sociedade valoriza excessivamente a parte racional. Do ponto de vista social, um homem que chore resvala para um aspeto feminino, um homem que seja racional é que é um homem forte, um homem como a sociedade acha que este deve ser" (E1).

37 Face a este contexto, a "crença de que os homens são, por natureza, mais contidos em relação à expressão emocional e afetiva" (E29) foi contestada por posições pessoais que reforçam a ideia da expressão emocional e afetiva como um produto de uma certa ordem social que, em geral, associa a expressão emocional e afetiva às mulheres, domesticando, dessa forma, os homens:

"Muitas vezes, pensa-se que um homem é insensível. O que acontece é que, culturalmente, nos impedem de expressar livremente as nossas emoções, 
obrigando-nos a suportar uma vida de pressão" (E3). "Nos homens é muito difícil lidar com as emoções. Eu penso que os homens, na generalidade, tentam esconder as emoções (...) porque não é próprio dos homens ter determinado tipo de emoções, especialmente em público (...) especialmente emoções como chorar" (E4). "Em geral, os homens reprimem muito mais a expressão das suas emoções e dos seus afetos. Um homem dificilmente assume que está triste. Quando tal acontece, mais do que tentar trabalhar a sua tristeza, muitas vezes os homens refugiam-se no álcool ou outro vício. Outros vêm para aqui [ao ciberespaço] na esperança de encontrar alguém para desabafarem mais livremente" (E31).

Todavia, e mesmo para aqueles participantes que fizeram uma apresentação de si como alguém que valoriza muito as emoções e a sua expressão, o peso da regulação social parece falar mais alto:

"Para mim as emoções são o principal da vida. Sem elas passamos a ser máquinas. Por exemplo, eu valorizo muito ir ver um pôr do sol ou ler um livro sobre um tema mais profundo. Mas a verdade é que não conheço muitos homens que digam o mesmo. Eu próprio não costumo dizê-lo" (E5).

\subsection{Homens por detrás da máscara}

Uma vez apresentada a incorporação dos ditos e interditos relativos à expressão emocional e afetiva, em particular no que aos homens diz respeito, Homens por detrás da máscara apresenta, como dissemos, diferentes vivências protagonizadas pelos participantes, habitualmente silenciadas nos palcos offline (por exemplo, família, amigos, colegas, local de trabalho, intimidade) e relacionadas com momentos sentidos como de especial vulnerabilidade. Os discursos que seguidamente se apresentam traduzem estratégias de orientação da expressão emocional e afetiva alimentadas por esquemas socialmente construídos que, em geral, desautorizam os homens a expressar emoções que impliquem vulnerabilidade:

"Quando fico mais triste, prefiro resguardar-me e pensar por mim próprio quais as decisões mais acertadas a tomar. Contudo, quando as coisas não me correm de feição, expludo com muita facilidade e sou mais agressivo na forma de me expressar" (E26).

"Quando me sinto magoado, normalmente guardo para mim; consigo, de alguma forma, controlar-me, embora as emoções possam estar lá. Às vezes, no meu dia a dia profissional, há uma ou outra situação mais complicada em que, lá está, dá-me vontade de chorar, mas não o faço. Consigo controlar-me ao máximo e faço-o porque não sei se a outra pessoa vai achar que é um sinal de fraqueza ou sensibilidade excessiva" (E7).

"Eu sou um homem bastante emotivo. Contudo, para chorar, procuro o lugar ideal para fazê-lo, um lugar solitário, preferencialmente a minha casa" (E31).

A propósito do choro, o próximo participante, pai de dois fi lhos, refere precisamente o facto de ser pai como fator desinibidor do próprio choro:

"É verdade que, em geral, continuamos a calar muito as emoções, em especial a fragilidade. Todos temos fragilidades e isso custa a admitir. No meu caso pessoal, não diria que me é fácil chorar, mas, quando me emociono e me vêm as lágrimas aos olhos, já não as tento conter e deixo-as sair. E tenho-o feito desde que sou pai. Talvez sinta que, por ser pai de dois fi lhos, já não tenho nada a provar em termos de masculinidade" (E33).

41 Por outro lado, a próxima passagem discursiva, relativa a um homem de 44 anos, casado, pai de dois fi lhos, em situação de desemprego prolongado, deu visibilidade aos sentires do homem por detrás da máscara: 


\begin{abstract}
"Sou um homem bastante emotivo, mas não sou uma pessoa de lágrima fácil. Sou particularmente sensível a situações de morte, desemprego prolongado, relacionamentos terminados... São situações que podem provocar-me estados de alma chorosos para desabafar. Senti particularmente vontade de chorar devido a não ter trabalho, sendo eu uma pessoa qualificada... Senti-me desaproveitado e desprezado. Nesses momentos, refugiei-me sozinho no meu quarto, onde não visse ninguém nem fosse visto por ninguém" (E32).
\end{abstract}

Por outro lado, o facto de se desejar uma relação afetiva que ainda não aconteceu, associado ao medo da "idade que não perdoa" (E1) e "aos outros que olham para nós e estranham estarmos sós com esta idade" (E1), foi apontado como motivo "de um sofrimento atroz, cuja partilha só consigo fazer com a minha terapeuta" (E1). Este refúgio por detrás da máscara surgiu em diversos discursos e relativamente a diferentes ocasiões, tal como é possível constatar: "Na altura em que rompi o meu relacionamento, senti uma mistura grande de sentimentos, mas ficaram guardados comigo" (E3).

Uma outra área explorada foi a das relações afetivas e amorosas. 0 próximo participante apresenta-nos a sua história, sobre a qual nos advertiu que "obviamente não tenho por hábito partilhá-la" (E33). Diz-nos então que:

[A primeira relação afetiva, no sentido conjugal] foi a minha iniciação sexual que, na altura [aos 20 anos], considerei tardia. Agora, acho que até foi melhor, [mas] na altura pensava que ia ser virgem aos 40 , mas se calhar foi melhor eu ter crescido emocionalmente antes de ter tido essa experiência. Tinha saído de casa, estava a estudar em (...), comecei a fazer e experimentar tudo o que não pude na adolescência por causa da minha mãe e da minha incapacidade para a enfrentar. 0 que é engraçado nessa relação é que essa rapariga com quem me iniciei só queria sexo e eu pensei que me tinha apaixonado. Quer dizer, depois de tanto tempo a querer uma fuck buddy, como dizem os americanos, encontro uma e fi co triste por não ser uma namorada tradicional. É que só estávamos juntos quando íamos para a cama. Por exemplo, se nos cruzássemos na universidade ou na rua ela era fria comigo. Por isso, quase não chegou a haver afeto, apenas sexo. A parte do sexo estava muito bem, era mesmo o que eu queria, só que depois comecei a querer aquelas coisinhas que nunca tinha tido como ir à praia com ela ou ao cinema, precisamente as coisas que pensava antes que não queria" (E33).

\title{
Discussão
} colocadas, emergiram duas configurações discursivas. Em Máscara para homem, os discursos produzidos pelos participantes deram visibilidade a uma forte configuração social que associa masculinidade a autocontrolo, facto que parece direcionar os homens para a incorporação da ideia de que relatar determinadas emoções constitui um sinónimo de fraqueza e, nesse sentido, uma ameaça à sua masculinidade. Contudo, os resultados permitem-nos justificar este autocontrolo, não à luz da natureza dos homens, mas antes à luz de uma exigência social que os associa a seres fortes e emocionalmente fortes e controlados.

Face a este contexto, os discursos desenvolvidos pelos participantes evidenciam uma oscilação discursiva que ilustra uma expressão emocional e afetiva socialmente autorizada e uma expressão emocional e afetiva socialmente punível de acordo com o género. De um modo geral, os resultados evidenciam que os homens são forçados a uma inibição da expressão das suas emoç̃oes e dos seus afetos, embora a irritação ou a agressividade constituam notórias exceções à regra. Não será por acaso que muitos 
estudos confirmaram já que os homens expressam a sua irritação mais frequentemente do que as mulheres (Fischer e Manstead, 2000; Frevert, 2011; Scheff, 1988; Seidler, 2007). Da mesma forma, não será coincidência o facto de os homens exibirem maior expressividade facial quando se trata de demonstrar irritação ou cólera do que quando se trata de medo. Tal facto vai também ao encontro dos resultados de Eisler (1995) e Sheff (1988). Long (1987) sustenta mesmo que a alta incidência de irritação e cólera por parte dos homens será o resultado de estes direcionarem emoções percebidas como menos masculinas para o canal expressivo da irritação, dado que esta estará mais de acordo com a identidade masculina hegemónica (Connell, 1995).

Nesse sentido, os resultados apresentados em Máscara para homem ditam e interditam as imagens (in)desejadas de masculinidade e reforçam a ideia social que associa os homens a seres emocionalmente controlados, tal como proposto por Jansz (2000), facto que concorre igualmente para a ideia de constrangimento como pré-requisito da performatividade (Vale de Almeida, 1995). Enquadramos, nesta linha de raciocínio, os esforços dos homens em influenciar diferentes audiências (Goffman, [1959] 1993) através dos seus desempenhos construídos em conformidade com uma fachada social pensada, numa perspetiva moderna e ocidental, para uma identidade fi xa associada a uma categoria rígida chamada de homem.

Uma vez visitados os Homens por detrás da máscara, foi possível desvendar diferentes vivências relativas à expressão emocional e afetiva, protagonizadas pelos participantes, sobre as quais habitualmente não se fala nos palcos offline. Os discursos apurados revelam posicionamentos distintos que influenciam diferentes práticas protagonizadas pelos participantes. Foram relatadas experiências pessoais que reforçam o grau de conformidade dos participantes quando, por exemplo, em contextos familiares, de intimidade ou profissionais, pela manifestação de comportamentos socialmente esperados de acordo com o género.

Associados a tais experiências, foram relatados, à semelhança dos resultados encontrados por Scheff (1988) sobre lesões ocultas ligadas à manutenção da masculinidade, episódios de dificuldade e sofrimento vividos quase sempre de forma silenciosa e solitária, facto que não dispensa uma problematização das condições em que os homens são socialmente fabricados, mas também das múltiplas (o)pressões a que se sujeitam e são sujeitados. Tal facto justifica um questionamento das práticas educativas desenvolvidas desde cedo, não apenas em família, mas nas instituições de educação formal, como é o caso da escola. No contexto das suas investigações em contexto escolar, nomeadamente no que respeita à expressão emocional e afetiva por parte dos rapazes, Brody (2000) revela que os grupos de pares reforçam e mantêm a conformidade com as regras relativas ao processo de expressão emocional, exibindo os comportamentos socialmente esperados, de acordo com o género, tornando-se socialmente mais aceites e vistos como os "fixes" ou "porreiros". Os rapazes mais populares são, de acordo com a autora, os que atuam de forma mais dura e agressiva, desafiam a autoridade dos adultos e se gabam de violar algumas das regras estabelecidas.

Também Jansz (2000) sustenta que a investigação tem revelado que os homens dificilmente revelam os seus sentimentos pessoais, tendendo antes a esconder a expressão das suas emoções, em particular o medo, a tristeza, a vergonha e a culpa, de resto, tal como os participantes por nós entrevistados. Tal facto pode ser compreendido como uma estratégia de reforço de uma imagem de masculinidade hegemónica (Connell, 1995), dado 
que a expressão de sentimentos mais afetuosos ou de carácter mais íntimo é geralmente interpretada como sinal de vulnerabilidade e fraqueza (Jansz, 2000).

Nesse sentido, a regulação da expressão emocional e afetiva, em particular em casos de fragilidade, parece conferir uma segurança percebida quanto à manutenção de uma imagem de si socialmente valorizada e distanciada de formas de masculinidade subordinada (Connell, 1995). Tal facto reforça a pertinência de uma análise da expressão emocional e afetiva em função da história e da cultura e menos dependente da natureza, tal como proposto por diferentes autores (por exemplo, Frevert, 2011; Harré, 1986; Lutz, 1990; Oatley, 1993). Reforça, ainda, a noção de regulação da expressão emocional e afetiva (Gross e Thompson, 2007) como estratégia de pertença a uma classe socialmente valorizada de homens e, consequentemente, a noção de masculinidades cúmplices (Connell, 1995).

Gostaríamos, antes de terminar, de relembrar que a escolaridade de 10 dos 17 participantes da presente investigação corresponde ao ensino superior. Por outro lado, a maioria dos participantes é branca, urbana e residente no litoral. Tal facto leva-nos a ponderar se as experiências de homens menos diferenciados e até menos habilitados para a utilização de computadores e para a navegação em espaços de conversação na internet nos trariam outros relatos e outros posicionamentos. Para concluir, diríamos que é a partir da perceção incorporada da ordem das coisas, estruturada em conformidade com as próprias estruturas de dominação imposta aos indivíduos - no caso concreto, aos homens - que podemos afirmar, corroborando Bourdieu ([1998] 1999), que os atos de conhecimento dos indivíduos são, por vezes, inequívocos atos de reconhecimento e de submissão. A este propósito, Bourdieu (Ibidem: 1) acrescenta:

"E também vi sempre na dominação masculina, e na maneira como é imposta e sofrida, o exemplo por excelência dessa submissão paradoxal, efeito daquilo que chamo a violência simbólica, violência branda, insensível, invisível para as suas próprias vítimas, que se exerce no essencial pelas vias puramente simbólicas da comunicação e do conhecimento ou, mais precisamente, pelo desconhecimento, do reconhecimento ou, no limite, do sentimento."

\section{BIBLIOGRAFIA}

ALFERES, V. (1997), Encenações e Comportamentos Sexuais: Para uma psicologia social das sexualidades. Porto: Edições Afrontamento.

ALARCÃO, M., RELVAS, A. P. (2002), Novas Formas de Família. Coimbra: Quarteto.

BRACONNIER, A. (1996) [1998], o Sexo das Emoções. Lisboa: Instituto Piaget.

BOURDIEU, P. ([1998] 1999), A Dominação Masculina. Oeiras: Celta.

BRAUN, V., CLARKE, V. (2006), "Using thematic analysis in psychology", Qualitative Research in Psychology, 3: 77-101. 
BRODY, L. R. (2000), “The socialization of gender differences in emotional expression: Display rules, infant temperament, and differentiation", in A. H. Fischer (ed.), Gender and Emotion: Social psychological perspectives. Cambridge: Cambridge University Press: 24-47.

CONNELL, R. W. (1995), Masculinities. Berkeley: University of California Press.

EISLER, R. M. (1995), “The relationship between masculine gender role stress and men's health risk: The validation of a construct", in R. F. Levant e W. S. Pollack (eds.), A New Psychology of Men. New York: Harper Collins: 229-252.

ELIAS, N. (2002), Teoria Simbólica. Oeiras: Celta Editora.

FABES, R. A., MARTIN, C. L. (1991), “Gender and age stereotypes of emotionality”, Personality and Social Psychology Bulletin, 17: 532-540.

FERGUSON, T. J., EYRE, H. L. (2000), “Engendering differences in shame and guilt: Stereotypes, socialization, and situational pressures", in A. H. Fischer (ed.), Gender and Emotion: Social psychological perspectives. Cambridge: Cambridge University Press: 254-276.

FISCHER, A. H., MANSTEAD, A. S. R. (2000), "The relation between gender and emotions in different cultures", in A. H. Fischer (ed.), Gender and Emotion: Social psychological perspectives. Cambridge: Cambridge University Press: 71- 94.

FIVUSH, R., BUCKNER, J. (2000), “Gender, sadness, and depression: The development of emotional focus through gendered discourse", in A. H. Fischer (ed.), Gender and Emotion: Social psychological perspectives. Cambridge: Cambridge University Press: 232-253.

FREVERT, U. (2011), Emotions in History: Lost and found. Budapest: Central European University Press.

\section{RESUMOS}

De acordo com as posições assumidas pelos estudos de género, os homens aprenderam, no contexto da modernidade ocidental, a regular as apresentações de si e a expressão emocional e afetiva, em resultado da incorporação de um modelo dominante que os associa à heterossexualidade, à racionalidade e ao autocontrolo. Neste artigo discute-se a ideia de regulação da expressão emocional e afetiva, a partir de um estudo realizado pelo autor, por referência à incorporação desenvolvida pelos homens de um modelo dominante que associa a razão à masculinidade e a emoção à feminilidade. Os resultados evidenciam que os homens são forçados a uma inibição da expressão das suas emoções e dos seus afetos, constituindo a irritação ou a agressividade notórias exceções à regra.

According to previous gender studies, men have learned to regulate how they present themselves and their emotional and affectional expression as the result of the incorporation of a dominant model which binds them to heterosexuality, rationality and selfcontrol. With this article, the author intends to analyze the concept of emotional and affective regulation. The discussion stems from a study that the author has previously conducted, and it will primarily focus on the man-made conception of a prevailing model that equates reason with masculinity and emotion with femininity. The results show that men are forced to inhibit the expression of their emotions and their affections, with irritation or aggressiveness being notorious exceptions to the rule.

Selon les études de genre, et d'une façon générale, les hommes auraient appris à réguler leur manière d'être et leur expression émotionnelle et affective, à la suite de l'incorporation d'un modèle dominant qui associe la rationalité et la maîtrise de soi à l'hétérosexualité. Cet article 
analyse, sur la base d'une étude menée par l'auteur, l'idée de régulation de l'expression émotionnelle et affective, en prenant pour point de départ l'incorporation développée par les hommes d'un modèle dominant qui associe la raison à la masculinité et l'émotion à la féminité. Les résultats montrent que les hommes sont contraints à une inhibition de l'expression de leurs émotions et de leurs affections, l'irritation ou l'agressivité constituant des exceptions à cette règle.

\section{ÍNDICE}

Mots-clés: Hommes, masculinités, régulation de l'expression émotionnelle et affective Palavras-chave: Homens, masculinidades, regulação da expressão emocional e afetiva. Keywords: Men, masculinities, regulation of affection and emotional expression.

\section{AUTOR}

\section{LUÍS SANTOS}

Professor Auxiliar da Faculdade de Ciências Humanas e Sociais da Universidade Fernando Pessoa.

Endereço de correspondência: Praça 9 de Abril 349, 4249-004 Porto, Portugal

lsantos@ufp.edu.pt 